\title{
LA CAMPAÑA TEATRAL DE RICARDO BAEZA E IRENE LÓPEZ HEREDIA (1927-1928): HISTORIA EXTERNA E INTERNA DE UNA COLABORACIÓN
}

\author{
ANDREW A. ANDERSON \\ University of Michigan
}

\begin{abstract}
El teatro que floreció en España durante los primeros decenios de este siglo fue esencialmente un teatro comercial y de gran público, muy popular tanto en Madrid como en los centros provinciales. Según la opinión de Jacinto Benavente expresada en una entrevista publicada en 1928, «nunca hubo tan buenos autores como ahora, ni tantos artistas de mérito, ni tanto ambiente de opinión, ni público tan bien dispuesto para escuchar y ver las obras de escena [...] Ganamos más que nunca» ${ }^{1}$. El teatro que el célebre dramaturgo describe en términos tan positivos y optimistas floreció a pesar de - a veces inconsciente de - los repetidos ataques de un sector intelectual minoritario y su diagnóstico, acertado pero desatendido, de una llamada «crisis del teatro» ${ }^{2}$. Estos escritores y críticos opinaban que la oferta teatral era casi siempre caducada, banal, repetitiva, falta de calidad y, en el peor de los casos, hasta perjudicial ${ }^{3}$. Al mismo tiempo, para demostrar que existían algunas obras de alta calidad y explorar nuevas maneras de montarlas, algunos pioneros, entre ellos Cipriano Rivas Cherif, Ricardo Baroja y Ramón del Valle-Inclán, lanzaban de vez en cuando un intento de teatro «artístico», teatro a menudo de aficionados y dirigido casi siempre a una elite reducida. Los conocidos proyectos de «El Mirlo Blanco» (1926-27), «El Cántaro Roto» (1926) y «El Caracol» (1928-29) son sintomáticos en este sentido y ya se han documentado ampliamente. Estas dos

1 En Federico NAVAS, Las esfinges de Talía o encuesta sobre la crisis del teatro, El Escorial, Imprenta del Real Monasterio de El Escorial, 1928, p. 4, citado por Dru DOUGHERTY, «Talía convulsa: la crisis teatral de los años 20», en Robert LiMA / Dru DOUGHERTY, 2 ensayos sobre teatro español de los 20, ed. César Oliva, Murcia, Universidad de Murcia, 1984, pp. 85-157 (p. 90).

2 El debate sobre tal «crisis» ha sido estudiado detenidamente por Dru DoUGHERTY en su ensayo «Talía convulsa...».

3 DOUGHERTY, «Talía convulsa...», p. 91.
\end{abstract}


visiones tan diferentes, que ponían el teatro o en su cénit o en su nadir, promovieron una especie de polarización que se expresaba a través de los consabidos binomios de la época: tradición-vanguardia, apogeo-crisis, statu quo-reforma, público-crítica, teatro comercial-aficionado, y un largo etcétera ${ }^{4}$.

Pero existía un tercer camino, una vía intermedia entre, por un lado, la diversión irreflexiva y el puro negocio y, por otro, la insistencia intransigente en el arte, usualmente a expensas de cualquier consideración empresarial. Cuando Ricardo Baeza aceptó el puesto de director artístico en la compañía que estaba formando la primera actriz Irene López Heredia en diciembre de 1927, ambos pensaban evidentemente en este tercer camino. No obstante esta actitud compartida, la colaboración y la campaña fueron, en sus orígenes, el resultado de la intersección de dos carreras teatrales que, hasta ese momento, habían seguido cursos muy distintos.

Irene López Heredia (1894-1962), nacida en Mazarrón (Murcia), se hizo actriz siendo muy joven; debutó en la Sociedad de Arte Español (un grupo de aficionados), y después de un aprendizaje en el Conservatorio y las compañías de R. Simó-Raso y de María Guerrero-Fernando Díaz de Mendoza, en 1914 entró en la compañía de Ernesto Vilches ${ }^{5}$. Unos años después, y unidos sentimentalmente, la pareja - primer actor y primera actriz- asumió la codirección de la compañía ${ }^{6}$; hicieron varias giras a América Latina, quedándose fuera de España un total de cinco años. En el verano de 1926 embarcaron otra vez para el Nuevo Mundo, pero su relación personal parece haberse deteriorado durante esta última tournée, exacerbada quizás por una larga y grave enfermedad que padeció Ernesto Vilches mientras estaban en Colombia ${ }^{7}$. Así, en el otoño de 1927 se separaron con bastante amargura y rencor, al parecer ${ }^{8}$, y a finales de noviembre, de vuelta

4 Dru DougherTy y María Francisca VILCHES DE FRUTOS, «Introducción», en El teatro en España entre la tradición y la vanguardia (1918-1939), ed. Dougherty y Vilches, Madrid, C.S.I.C. / Fundación Federico García Lorca / Tabapress, 1992, p. 13.

5 Antonio DE LA VILLA, «De allá para acá. La muchacha que todo lo tiene», La Libertad, 1-XII-1927, p. 3; Cipriano DE RIVAS CHERIF, Cómo hacer teatro: Apuntes de orientación profesional en las artes y oficios del teatro español, ed. Enrique de Rivas, Valencia, Pre-Textos, 1991, pp. 73, 186. Hay un artículo biográfico sobre LÓPEZ HEREDIA en la Enciclopedia universal ilustrada europeo-americana: Suplemento anual, 1961-1962, Madrid, Espasa-Calpe, 1966, pp. 249-250; véase también El Caballero Audaz, «Nuestras visitas. Irene López Heredia», La Esfera, núm. 262 (4-I-1919), s.p.

6 No queda del todo claro si se casaron de verdad, o si sólo vivían como matrimonio. He encontrado una referencia al «niño Pepito Vilches», en ANÓNIMO, «Teatro Principal. Irene López Heredia», La Región (Orense), 4-III-1928, p. 5, lo que sugiere que la pareja tenía un hijo.

7 El artículo más documentado sobre la ruptura es la entrevista que hizo Enrique González Fiol al actor: «Pigmalión sin su escultura. Nuevo rumbo de Ernesto Vilches», La Esfera, núm. 730 (31-XII-1927), pp. 8-9.

8 En las repetidas declaraciones a la prensa, la ruptura se presentaba como una separación amistosa, sin odio ni recriminaciones, pero el contenido de una nota de Vilches 
de América, tanto el actor como la actriz llegaron a Madrid, independientemente, cada uno con el propósito de organizar su propia compañía ${ }^{9}$.

Por su parte, Ricardo Baeza (1890-1956), nacido en Bayamo (Cuba) de padres españoles, era la fuerza motriz de la Compañía Dramática «Atenea» que había fundado en 1919, siendo durante su breve existencia su director artístico. Pero casi seguramente tenía Baeza mayor fama como traductor de una amplia gama de obras teatrales extranjeras modernas, como exigente crítico teatral, y como autor de numerosos artículos sobre el problema o la crisis teatral. En 1927, tras un paréntesis de dos años (1924-25) en Palma de Mallorca, volvió de nuevo a Madrid con su familia, entregado a la vida literaria y periodística ${ }^{10}$.

Recién separada del que, además de compañero íntimo, había sido su mentor y colega profesional, López Heredia debió pensar en la ventaja de formar su primera compañía «autónoma» secundada por un director artístico capacitado y talentoso. Al hacerse pública la noticia de su acuerdo, comentó un periodista:

El hecho de que al formar compañía llame la bellísima actriz a un artista y escritor tan selecto como Ricardo Baeza, tan apartado de todos los comadreos y rutinas al uso en nuestros teatros, prueba una ambición y un propósito generoso y desusado al llevar a nuestro teatro un afán de renovación, tan poco frecuente, por desgracia, entre nosotros... ${ }^{11}$

Irene conocía a Ricardo personalmente desde hacía unos años, ya que éste, en 1925 y 1926, había propuesto a la compañía Vilches-López Heredia

a Baeza (en una tarjeta de visita, sin fechar), y de una carta de Vilches a Heredia (escrita desde Cartagena, Colombia, el 13 de octubre de 1927), ambas conservadas en el archivo particular de la familia Baeza, revela una situación mucho más conflictiva.

9 ANÓNIMO, «Las brujas informadoras. Aquelarre teatral», Informaciones, 28-XI1927 , p. 8, informa que Vilches llegó a la capital el 26 de noviembre, y a principios de diciembre iba a formar una compañía para presentarse hacia el 15 ó 20 del mismo mes en el teatro Infanta Beatriz de Madrid. Según el mismo reportaje, la Heredia «anuncia su llegada a la corte, donde procederá a la formación que tenía anunciada». ANóNIMO, «Crónicas y noticias teatrales de "Informaciones". Las brujas informadoras. Aquelarre teatral», Informaciones, 5-XII-1927, p. 9, recogió el rumor que la primera actriz de Vilches sería «la guapa Carmen Jiménez». En la entrevista, ya citada, de Vilches con Enrique González Fiol, se mencionan «la Parody» y Jiménez.

10 Para más información general y biográfica sobre Baeza, véase Andrew A. ANDERSON, «Ricardo Baeza y el teatro», Anales de la Literatura Española Contemporánea, XIX, núm. 3 (1994), 229-240. Opinó un rotativo, refiriéndose a la colaboración entre Baeza y López Heredia: «Nadie mejor preparado que el fino escritor, tan artista, tan culto, tan noblemente consagrado a la crítica, al ensayo, de labor tan varia e intensa, ya en el periodismo y en las revistas, donde ha aportado una cultura excepcional, una visión limpia e intensa y una imparcialidad y valentía poco frecuentes en nuestros menguados medios literarios»: ANÓNIMO, «Correo de teatros. [...] ILH y RB», Informaciones, 17-XII-1927, p. 6.

11 ANÓNIMO, «Correo de teatros. [...] ILH y RB», Informaciones, 17-XII-1927, p. 6. 
la inclusión en su repertorio de una serie de traducciones hechas por él y de alguna obra original de su amigo Claudio de la Torre ${ }^{12}$. En cuanto a su aceptación de la oferta, Baeza explicó a dos reporteros que:

- Hacía ya tiempo que Irene López Heredia tenía deseos de realizar esta campaña de arte depurado.

...yo le había prometido hace algún tiempo a la señora Heredia, solicitado por ella, que si alguna vez se independizaba yo estaría a su lado y trataría de orientarla según mi mejor saber y entender ${ }^{13}$.

Sin embargo, sus motivos iban mucho más allá de un antiguo compromiso personal. Tenemos que recordar que, en las páginas de $E l \mathrm{Sol}$, entre el 19 de octubre de 1926 y el 22 de enero de 1927, Baeza había publicado una serie de no menos de veinte artículos con el título general de «En torno al problema del teatro», en los que había analizado detenidamente la escena española del momento, identificando las personas y los factores responsables de su decadencia, y propuesto unos remedios prácticos. Dentro de este contexto es cómo debemos entender su convicción de que:

...a las palabras debe empezar a suceder la acción; al plan de reforma, la realización de ella.

y, un poco más abajo, su comentario sobre el requerimiento que le había hecho López Heredia:

Aunque mi apetencia momentánea no me llamaba quizá por este camino, no me he creído con derecho a rehusar la dirección de una empresa en la que existía la posibilidad de llevar a cabo algo de lo que he venido preconizando desde hace tiempo... ${ }^{14}$

De la misma manera, a la luz de estos antecedentes se aprecia mejor su sentimiento de responsabilidad y obligación ineludibles:

Me anima además a ello, y hasta me obliga casi como un deber moral, la esperanza de poder llevar a cabo una campaña de cierta utilidad para el teatro español. A pesar de que esto viene a desorganizar considerablemente mi vida, encarrilada en otro sentido, no me he creído con derecho a rehusar.

12 Seis cartas de Ernesto Vilches a Ricardo Baeza, desde agosto 1925 hasta junio 1926, en el archivo Baeza.

13 Emilio CERRILLO, «Entrevistas. Hablando con RB. El valor más importante del teatro español es Jacinto Grau», El Norte de Castilla (Valladolid), 25-III-1928, p. 3; ANÓNIMO, «Información teatral. Los planes de RB e ILH», El Sol, 8-XII-1927, p. 5.

14 Ricardo BAEZA, «De la necesidad de una intervención del Estado», El Sol, 15XII-1927, p. 8. 
...tendré la tranquilidad de conciencia de haber acudido al llamamiento cuando he creído que se podía hacer algo en pro de nuestro teatro ${ }^{15}$.

Durante el mes de diciembre de 1927 , la prensa madrileña dedicó bastante espacio a la iniciativa de López Heredia y Baeza, lo que dio ocasión a que las normas y los criterios de la agrupación - casi inauditos en el teatro «comercial» de la época- fuesen delineados en detalle por éste. Para empezar, Baeza aseveró que su propósito era el de:

- Hacer buenas comedias y hacerlas bien. Y tratar de demostrar la relativa inocencia del público, que ya sostuve en mi campaña teatral del año pasado; demostrar que si al público no le gustan las obras buenas, como afirman los empresarios y los actores que no las hacen, es, ante todo, porque no se las dan con gran frecuencia ${ }^{16}$.

Pero no iban a intentarlo todo a la vez, porque Baeza sabía perfectamente que la táctica indicada, bajo estas circunstancias, era una reforma paulatina y no una revolución precipitada:

Nosotros nos proponemos hacer, en un principio, comedias agradables, de público y, al mismo tiempo, de calidad literaria. Más adelante procuraremos ir dando cosas un poco más difíciles, presentando al público español lo que se hace de más nuevo por esos escenarios europeos ${ }^{17}$.

Nuestro propósito para comenzar no es demasiado revolucionario, y no se deberá pedirnos milagros. Las grandes empresas de arte no se improvisan, y requieren su tiempo. Como ya indicaba, nuestro objeto inmediato es hacer y presentar bien unas cuantas buenas comedias, demostrar al público que las obras de cierto decoro literario también pueden ser divertidas ${ }^{18}$.

\footnotetext{
15 ANÓNIMO, «Información teatral. Los planes de RB e ILH», El Sol, 8-XII-1927, p. 5.

16 Idem, id.

17 Idem, id. En una carta de Claudio de la Torre, escrita desde Bilbao el 10 de diciembre, éste expresó a Baeza su júbilo: «iQué alegría al conocer sus espléndidos proyectos! Aun con El Sol entre las manos, dudando del milagro», para luego ofrecerle unos consejos: «De acuerdo, además, con toda la orientación del proyecto que conozco. Tacto y seguridad en el paso. Dar en falso los menos posibles. Para ello - si a usted no le importa que yo opine- mucho cuidado con las traducciones, que hay siempre que acortarlas sin reparos. Mucho cuidado, también, con las innovaciones. De éstas, por el momento, las que estén logradas de verdad. Tiempo llegará para los ensayos, cuando exista, por lo menos, un público de obras verdaderas. Lo otro será su consecuencia».

18 Ricardo BAEZA, «De la necesidad de una intervención del Estado», El Sol, 15 XII-1927, p. 8. Veáse también la formulación de sus intenciones hecha por López Heredia: «...mostraremos en España lo más selecto de los escenarios extranjeros, empezando, como es natural, por las obras más fácilmente asimilables para irnos elevando poco a poco. Queremos llegar al límite extremo de la sensibilidad del público español, que no está tan bajo como muchos suponen», en ANÓNIMO, "Hacer buenas comedias y hacerlas bien". ILH nos habla de sus propósitos», Heraldo de Madrid, 17-XII-1927, p. 6.
} 
Esta estrategia de ir ganando terreno lentamente, de quitarle poco a poco al público la costumbre de obras fáciles para luego reemplazarlas con otras jugosas y serias, se compaginaba con otra meta básica de la empresa:

La compañía de Irene López Heredia se propone realizar gradualmente la tarea de reeducar a nuestro gran público - estragado por el astracán y la «comedia de té y amena conversación»- y cooperar así a la difícil obra del renacimiento teatral. Por eso es escogido el repertorio - obras de positivo mérito artístico- y por eso en su formación ha atendido a la creación de una compañía donde se busque, no el éxito personal de determinados elementos, sino el logro de interpretaciones acabadas por la labor de todos y a costa de sacrificios de labores individuales. Organización cuya falta veníamos notando desde hace muchos años en el panorama de nuestra farándula ${ }^{19}$.

Aparte de estos puntos básicos, que constituían la razón de ser esencial de la compañía nueva:

-Otras novedades, relativas, serán un cuidado del conjunto algo más estricto del que se suele en las compañías españolas, y una presentación escenográfica moderna, sintética, que sea un placer para los ojos en sí misma. En este respecto no se escatimarán esfuerzos ni gastos ${ }^{20}$.

En efecto, reclutaron a Salvador Bartolozzi como escenógrafo, quien diseñó la mayoría de los decorados (los otros fueron responsabilidad del no menos famoso Manuel Fontanals):

- Salvador Bartolozzi, el maravilloso artista que es un decorador y escenógrafo moderno como hay pocos, llevará el peso del montaje de las obras en lo que concierne a decorado, luz, indumentaria, atrezzo, etcétera. Es propósito del director artístico, Ricardo Baeza, dar a las obras una presentación escenográfica moderna, sintética: para decirlo con sus propias palabras: «Que sea un placer para los ojos en sí misma» ${ }^{21}$.

Además, contrataron a un elenco de actores y actrices de calidad, dispuestos todos a participar activamente en un disciplinado esfuerzo de grupo:

19 T. B., «De teatros. El debut de esta tarde», El Carbayón (Oviedo), 7-III-1928, p. 1. Sobre la combinación necesaria de labor docente y demostración práctica véase también Ricardo Baeza, «De la necesidad de una intervención del Estado», El Sol, 15XII-1927, p. 8.

${ }^{20}$ ANÓNIMO, «Información teatral. Los planes de RB e ILH», El Sol, 8-XII-1927, p. 5.

21 ANÓNIMO, «"Hacer buenas comedias y hacerlas bien". ILH nos habla de sus propósitos», Heraldo de Madrid, 17-XII-1927, p. 6. Sobre el talento escenográfico de Bartolozzi, véase David Vela CERVERA, «El estreno en Madrid de El señor de Pigmalión de Jacinto Grau (18-V-1928): la plástica escénica de Salvador Bartolozzi», Anales de la Literatura Española Contemporánea, XX, núm. 3 (1995), 439-461. 
...me encuentro orgulloso del conjunto que hemos logrado. Esto era lo esencial en nosotros, porque lo que consideramos fundamental en la puesta en escena es eso: el conjunto cuidado, escrupuloso, el tono general de la compañía, la adecuación de las partes para dar la impresión dramática total en cada escena ${ }^{22}$.

Aparte de López Heredia como primera actriz, Baeza como director artístico, y Bartolozzi como director escenográfico, en el grupo reunido figuraban como primeros actores José Bruguera ${ }^{23}$ y el joven Antonio Vico; como actor de carácter Juan Espantaleón; como actores Ramón Camarero, Carlos Díaz, Julio Goróstegui, Alejandro Maximino, José Mora, Tomás Norro y Tomás Venegas; como actriz de carácter Dolores Valero; como actrices Carmen Caballero, Asunción Camarero, Amelia Costa, Ana María Custodio, Carmen Díaz de Tejada, Carmen Nieto, Herminia Peñaranda (la esposa de Jacinto Grau) y María Victorero; como apuntador Manuel Agasti (luego Manuel Gutiérrez); como traspunte Manuel Perrín; como jefe maquinista José Aliaga; y como representante Justo Norro ${ }^{24}$.

Durante la primera quincena de diciembre la nueva compañía ensayó todos los días en Madrid y, según se decía, gastó «un dineral en decorados y muebles», preparándose con toda rapidez para su inminente traslado a Zaragoza donde iba a debutar, primera etapa de una prolongada gira por las provincias norteñas ${ }^{25}$. Gracias a la prensa de la época, ha sido posible reconstruir casi por completo el itinerario, la cronología y el repertorio de la compañía, desde su presentación en Zaragoza el 20 de diciembre de 1927 hasta su despedida al fin de la corta temporada de Pascua en Barcelona el 21 de mayo de $1928^{26}$. En cuanto a su desplazamiento geográfico y sus

\footnotetext{
22 ANÓNIMO, «"Hacer buenas comedias y hacerlas bien". ILH nos habla de sus propósitos», Heraldo de Madrid, 17-XII-1927, p. 6. El artículo publicitario ANóNIMO, «Alta comedia en el Principal. La Compañía de Irene López Heredia», El Diario de Pontevedra (Pontevedra), 27-I-1928, p. 2, hace alarde de «su disciplinadísimo elenco».

${ }^{23}$ Quien reemplazó, en el último momento, a Luis Peña: ANóNIMO, «Información teatral. [...] La compañía de ILH», La Voz, 12-XII-1927, p. 2.

24 Aunque la lista varió un poco, con algunas bajas y adiciones, la enumeración dada aquí ofrece el perfil más típico de la compañía. La encargada de la ejecución de los decorados era la Empresa Escenográfica Española dirigida por Carlos Merino.

25 ANÓNIMO, «Informaciones teatrales. Espectáculos que se darán en Zaragoza», $E l$ Noticiero (Zaragoza), 8-XII-1927, p. 2; ANÓNIMO, «En los teatros. Ya tiene primer actor la compañía de ILH», Heraldo de Aragón (Zaragoza), 9-XII-1927, p. 6; ANóNIMO, «Información teatral. [...] La compañía de ILH», La Voz, 12-XII-1927, p. 2. La compañía llegó a Zaragoza el 17 de diciembre, para realizar allí los últimos ensayos de conjunto: ANÓNIMO, «De los teatros. La compañía LH», El Noticiero (Zaragoza), 18-XII1927, p. 4. Tanto Baeza como Bartolozzi estuvieron presentes para el debut el día 20.

26 En los reportajes de diciembre, queda claro que tenían el proyecto de volver a Madrid la primavera siguiente a uno de los principales teatros (más tarde López Heredia nombraría el Lara): ANóNIMO, «Información teatral. Los planes de RB e ILH», El Sol, 8-XII-1927, p. 5; ANÓNIMO, "Hacer buenas comedias y hacerlas bien". ILH nos habla
} 
actuaciones en las distintas ciudades, el cuadro sinóptico siguiente ofrece los detalles más importantes:

\begin{tabular}{|l|l|r|c|}
\hline \multicolumn{1}{|c|}{ Lugar } & \multicolumn{1}{|c|}{ Fechas } & $\begin{array}{c}\text { Número } \\
\text { de días }\end{array}$ & $\begin{array}{c}\text { Número de } \\
\text { representaciones }\end{array}$ \\
\hline Zaragoza & 20 diciembre 1927-9 enero 1928 & 21 & 37 \\
Descanso & 10 enero 1928-13 enero 1928 & 4 & - \\
Vitoria & 14 enero 1928-17 enero 1928 & 4 & 8 \\
Descanso & 18 enero 1928-19 enero 1928 & 2 & - \\
Vigo [1] & 20 enero 1928-29 enero 1928 & 10 & 22 \\
Pontevedra [1] & 30 enero 1928-1 febrero 1928 & 3 & 6 \\
La Coruña & 2 febrero 1928-7 febrero 1928 & 6 & 13 \\
El Ferrol & 8 febrero 1928-11 febrero 1928 & 4 & 8 \\
Descanso & 12 febrero 1928 & 1 & - \\
Lugo & 13 febrero 1928-15 febrero 1928 & 3 & 7 \\
Orense [1] & 16 febrero 1928-17 febrero 1928 & 2 & 4 \\
Vigo [2] & 18 febrero 1928-21 febrero 1928 & 4 & 9 \\
Descanso & 22 febrero 1928- ¿24? febrero 1928 27 & $i 3 ?$ & - \\
¿Santiago de & 25 febrero 1928-27 febero 1928? 28 & $i 3 ?$ & $i 6 ?$ \\
Compostela? & ¿2 febrero 1928- 1 marzo 1928 & 3 & 6 \\
Pontevedra [2] & 2 marzo 1928-4 marzo 1928 & 3 & 6 \\
Orense [2] & 5 marzo 1928-6 marzo 1928 & 2 & - \\
Descanso & 7 marzo 1928-15 marzo 1928 & 9 & 19 \\
Oviedo & 16 marzo 1928 & 1 & - \\
Descanso & 17 marzo 1928-20 marzo 1928 & 4 & 8 \\
León & 21 marzo 1928 & 1 & - \\
Descanso & 22 marzo 1928-26 marzo 1928 & 5 & 10 \\
Valladolid & 27 marzo 1928-6 abril 1928 & 11 & - \\
Descanso & 7 abril 1928-21 mayo 1928 29 & 45 & 92 \\
Barcelona & & & \\
\hline
\end{tabular}

Durante los primeros meses de la tournée, Baeza viajó con la compañía a la mayoría de las ciudades donde actuaba, regresando a Madrid de vez en cuando. Aprovechó su papel como director artístico para dar unas conferencias no sólo en algunos de los lugares visitados sino también en otros cercanos o en su ruta. Dictó una conferencia titulada «Clasicismo y romanticismo» en Burgos, San Sebastián, Bilbao y La Coruña (17 de ene-

de sus propósitos», Heraldo de Madrid, 17 diciembre 1927, p. 6. No sabemos cuándo ni bajo qué circunstancias cambió el plan, con la resultante desviación a la ciudad condal.

27 En 1928 el miércoles de ceniza cayó el 22 de febrero.

28 Hay una carta de López Heredia a Baeza fechada en Santiago el 26 y 27, en la que se refiere a ensayos y representaciones. No hemos podido acceder a periódicos de esta ciudad de las fechas señaladas.

29 En 1928 el sábado de Gloria cayó el 7 de abril. 
ro, 18 de enero, 19 de enero y 10 de febrero, respectivamente) ${ }^{30}$, pero más interesante para nuestros propósitos presentes es otra, titulada «El carro de Tespis. Una ojeada al teatro y a nuestro actual panorama escénico», que leyó en Vigo, Oviedo y Valladolid (28 de enero, 6 de marzo y 27 de marzo, respectivamente) ${ }^{31}$. En Vigo, por ejemplo, la conferencia tuvo una relación directa con la actuación de la compañía, ya que fue dictada durante el primer entreacto de la función de la tarde - una representación de María Victoria de Manuel Linares Rivas- y desde el proscenio del teatro Tamberlick ${ }^{32}$. En Oviedo la misma charla se leyó en la víspera del debut de la compañía en esa ciudad, y en Valladolid el día después de la despedida de la companía, en ambos casos en el Ateneo correspondiente.

En esta conferencia, a todas luces casi idéntica en las tres ocasiones, Baeza empieza por establecer que el teatro no es sólo «una actividad puramente recreativa» sino que «el teatro es también un factor moral y social de máxima importancia». A continuación habla de la decadencia generalmente aceptada de la escena española contemporánea, critica el retraso de la escenografía española en comparación con el resto de Europa, y asevera que:

...nuestra actual literatura dramática presenta una marcada uniformidad y monotonía, una falta de diversidad y de hondura, y un [...] predominio del elemento cómico y realista sobre las demás formas y variedades del arte dramático... ${ }^{33}$

condición que según él hallaba su más aguda manifestación en la predominancia del «astracán» ${ }^{34}$. Lamenta no sólo esta «supremacía» en el gusto popular sino también el efecto de este fenómeno sobre los otros géneros más «altos», influencia que caracteriza de «rebajadora y letal». Llama la atención sobre «la dificultad del advenimiento de los autores noveles a

30 Véase la versión publicada: Ricardo BAEZA, Clasicismo y romanticismo, Colección El Libro del Pueblo, núm. 23, serie VIII-04, Madrid, Compañía Ibero-Americana de Publicaciones, s.f. [c. 1930-32].

31 Aparte de estas dos conferencias formales, Baeza también leyó un trabajo en el teatro el día del homenaje a los hermanos Álvarez Quintero, el 6 de febrero de 1928, teatro Rosalía de Castro, La Coruña, función de noche de Amores y amoríos: ANÓNIMO/ Ricardo Baeza, «En el "Rosalía Castro". La conferencia de Baeza», El Orzán (La Coruña), 7-II-1928, p. 1.

${ }_{32}$ ANÓNIMO, «RB, conferenciante. "El carro de Tespis"», Faro de Vigo (Vigo), 27I-1928, p. 3.

33 Ricardo BAEZA, «Folletones de "El Pueblo Gallego". "El carro de Tespis". Una ojeada al teatro y a nuestro actual panorama escénico. [Continuará.]», El Pueblo Gallego (Vigo), ¿29/30?-I-1928, recorte s.f. y s.p. en el archivo Baeza.

${ }_{34}$ Ricardo BAEZA, «Folletones de "El Pueblo Gallego". "El carro de Tespis". Una ojeada al teatro y a nuestro actual panorama escénico. [Conclusión.]», El Pueblo Gallego (Vigo), ¿30/31?-I-1928, recorte s.f. y s.p. en el archivo Baeza. 
nuestra escena», lo que representaba un «obstáculo capital [...] para la renovación de nuestro teatro» ${ }^{35}$. En cuanto a la situación en general, dice que mientras que todos los factores tienen cierta responsabilidad - público, actores, autores, críticos y empresarios-, él «achacaría la culpabilidad mayor a los autores [consagrados]». Y para terminar, hace explícito el vínculo entre estas ideas y su actividad presente:

Así, en el campo reducidísimo de esta compañía, en nuestro modestísimo marco, hemos de tratar de contribuir a esa obra de saneamiento. Una ardiente vocación de servicio a la causa común del arte anima a Irene López Heredia y [sus] compañeros esforzados y fervorosos ${ }^{36}$.

El vínculo también se evidenciaba en otro diagnóstico ofrecido en una entrevista de fecha cercana:

Para llevar a cabo una labor eficaz, no existe más medio que procurar que todas las compañías tengan su director artístico, pero nunca encomendada esta misión - quizás la más importante- a un actor. Son cosas incompatibles. Una cosa es el director artístico y otra el actor, cuyo papel debe reducirse a hacer las comedias. A causa de esta desorganización la literatura dramática no tiene estímulo ${ }^{37}$.

Las carreras de los principales colaboradores, la publicidad inicial, los motivos y las intenciones expresados, el itinerario y la cronología de la compañía, las ideas esgrimidas por Baeza en sus conferencias y entrevistas, todo contribuye al contexto vital y artístico dentro del cual podemos analizar y evaluar, con una apreciación más equilibrada de los matices, la elección de obras para el repertorio y la frecuencia de su representación. En el curso de los cinco meses precisos que duró la colaboración, la compañía trabajó unos 129 días y «descansó» 25 , aunque gran parte de este tiempo «libre» debe de haberse dedicado a ensayar, viajar de ciudad a ciudad, instalarse en un nuevo teatro, o preparar los baúles para partir. En los 129 días «activos» dieron unas 261 representaciones de 19 obras de 15 autores (7 españoles y 8 extranjeros).

Por orden alfabético de autor, y manteniendo esta división geográfica básica, las obras y autores fueron:

Amores y amoríos (1908) y Tambor y cascabel (1927) de Serafín (18711938) y Joaquín (1873-1944) Álvarez Quintero;

Lo cursi (1901) y Rosas de otoño (1905) de Jacinto Benavente (1866-1954);

35 Idem, id.

36 Idem, id. Para otros resúmenes, véanse ANÓNIMO, «En el Ateneo. Brillante conferencia de D. RB», El Carbayón (Oviedo), 7-III-1928, p. 1, y ANóNIMO, «Conferencias y cursillos. En el Ateneo. Conferencia de don RB», El Norte de Castilla (Valladolid), 28-III-1928, p. 2.

37 Emilio CERRILLO, «Entrevistas. Hablando con RB. El valor más importante del teatro español es Jacinto Grau», El Norte de Castilla (Valladolid), 25-III-1928, p. 3. 
La Dolores (1892) de José Feliú y Codina (1847-1897);

Mimí Valdés (1926) de José Fernández del Villar Granados (1888-1941);

El caballero Varona (escrito 1925, estrenado 1928, publicado 1929) de Jacinto Grau (1877-1958);

La mala ley (1923) y María Victoria (1904) de Manuel Linares Rivas (1867-1938);

Así son todas (1925) de Irene López Heredia (1894-1962);

Los caballitos de madera (Les Chevaux de bois) (1923) de André Paul Antoine ( $i \quad$ - ?) \& Maxime Léry (1885- $i \quad$ ?), traducción de A.S. de Heredia y Arturo Mori;

La máscara y el rostro (La maschera e il volto) (1916) de Luigi Chiarelli (1880-1947), traducción de A. Fernández Lepina \& Enrique Tedeschi;

El corazón manda (Le Coeur dispose) (1912) de Francis de Croisset (pseudónimo de Frantz Wiener) (1877-1937), traducción de Salvador Vilaregut;

Entre gente bien (Our Betters) (1917), traducción de Ricardo Baeza, y Lady Frederick (1907), traducción de Federico Reparaz, ambas de W. Somerset Maugham (1874-1965);

El camino de Francia (The Dover Road) (1921) de A.A. Milne (1882-1956), traducción de Ricardo Baeza;

Cándida (Candida) (1895) de George Bernard Shaw (1856-1950), traducción de Julio Broutá;

Un marido ideal (An Ideal Husband) (1895) de Oscar Wilde (1856-1900), traducción de Ricardo Baeza; y

Puesta del sol (Les Ailes brisées) (1920) de Pierre Wolff (1865-1930), traducción de Gonzalo Sebastián.

Quizás aun más interesante que esta enumeración es la frecuencia con que estas obras subieron a las tablas durante los cinco meses de colaboración. Estos datos aparecen en el cuadro sinóptico siguiente, donde podemos observar una división bastante nítida entre las primeras siete obras y las demás:

\begin{tabular}{|l|l|c|}
\hline \multicolumn{1}{|c|}{ Autor } & \multicolumn{1}{|c|}{ Obra } & \multicolumn{1}{|c|}{$\begin{array}{c}\text { Número de } \\
\text { representaciones }\end{array}$} \\
\hline Hermanos Álvarez Quintero & Tambor y cascabel & 35 \\
W. Somerset Maugham & Lady Frederick & 34 \\
Francis de Croisset & El corazón manda & 32 \\
Oscar Wilde & Un marido ideal & 28 \\
Jacinto Grau & El caballero Varona & 23 \\
Jacinto Benavente & Rosas de otoño & 20 \\
Antoine \& Léry & Los caballitos de madera & 18 \\
Jacinto Benavente & Lo cursi & 9 \\
\hline
\end{tabular}




\begin{tabular}{|l|l|c|}
\hline \multicolumn{1}{|c|}{ Autor } & \multicolumn{1}{|c|}{ Obra } & $\begin{array}{c}\text { Número de } \\
\text { representaciones }\end{array}$ \\
\hline Pierre Wolff & Puesta del sol & 9 \\
Hermanos Álvarez Quintero & Amores y amoríos & 8 \\
Manuel Linares Rivas & María Victoria & 8 \\
José Feliú y Codina & La Dolores & 7 \\
George Bernard Shaw & Cándida & 6 \\
Luigi Chiarelli & La máscara y el rostro & 6 \\
Manuel Linares Rivas & La mala ley & 3 \\
W. Somerset Maugham & Entre gente bien & $1{ }^{38}$ \\
Irene López Heredia & Así son todas & 1 \\
A.A. Milne & El camino de Francia & 1 \\
José Fernández del Villar & Mimí Valdés & $i 8 ?^{39}$ \\
Sin identificar & Sin identificar & \\
\hline
\end{tabular}

Al examinar este repertório, debemos recordar el plan esbozado por Baeza en su primera entrevista:

- Sostendremos en el cartel algunas de las obras ya hechas por la señora Heredia, en que ella obtiene un éxito personal y que al mismo tiempo son de un perfecto decoro literario. [...] De estrenos haremos algunas de las mejores comedias extranjeras de estos últimos tiempos... ${ }^{40}$

En efecto, sabemos que López Heredia ya había aparecido, en años previos, en: Lady Frederick (22 marzo 1923; 25 noviembre 1925; 24 junio 1926), El corazón manda (10 enero 1920; 3 noviembre 1925; 19 junio 1926), Un marido ideal (21 octubre 1925), Rosas de otoño (21 enero 1920), Los caballitos de madera (27 octubre 1925; 17 junio 1926), Puesta de sol (11 noviembre 1925), María Victoria (17 octubre 1918; 25 febrero 1920), La Dolores (12 enero 1926), y Así son todas (22 noviembre 1925) ${ }^{41}$, más La máscara y el rostro, Lo cursi, y La mala ley ${ }^{42}$. Por otro lado, eran

38 Esta corta obra, subtitulada «Monólogo que parece diálogo», se representó en la misma sesión de tarde con La Dolores el 13 de mayo en Barcelona. Por eso se registran 262 obras representadas en 261 representaciones.

${ }^{39}$ Las ¿seis? representaciones de Santiago de Compostela, más las dos de la última noche en El Ferrol, cuando el estreno de El caballero Varona fue aplazado en el último momento y la obra sustituida por otra no identificada.

40 ANÓNIMO, «Información teatral. Los planes de RB e ILH», El Sol, 8-XII-1927, p. 5.

41 Dru Dougherty y María Francisca VILCheS DE Frutos, La escena madrileña entre 1918 y 1926. Análisis y documentación, Madrid, Fundamentos, 1990. Las fechas se refieren al estreno o al primer día de reposición de la obra en cuestión. En el catálogo de Dougherty y Vilches estas obras reciben los números 1412, 655, 1631, 2373, $329,2222,1625,844$ y 214 , en las pp. $319,240-241,345,424,201,406,343,259$ y 188 , respectivamente.

42 Esta lista suplementaria se compone de obras que no aparecen en Dougherty y Vilches pero que están identificadas como reposiciones en ANÓNIMO, «Información tea- 
rigurosamente estrenos en España: El caballero Varona, Cándida, Entre gente bien y El camino de Francia; Tambor y cascabel era un estreno en provincias ${ }^{43}$.

Como se puede apreciar fácilmente, aunque el plan anunciado por Baeza sugería un equilibrio entre unas y otros, en la práctica la proporción de obras de repertorio montadas de nuevo (por lo menos doce) resultó muy superior respecto a los estrenos (cuatro). Esta observación se confirma plenamente si examinamos las listas de obras nombradas en entrevistas e informes publicitarios ${ }^{44}$. Por un lado, entre las obras anunciadas en las que López Heredia ya había actuado, sólo una, El admirable Crichton (1902) de Sir James Barrie (1860-1937), no llegó a las tablas durante esta gira. Por otro lado, entre los estrenos anunciados, hay nueve obras que nunca fueron representadas: una composición original, Tic-Tac (escrito 1924-26, estrenado 1930, publicado 1932), de Claudio de la Torre (1895-1972), cinco obras británicas, Amor sagrado y profano (Sacred and Profane Love) (1919), de Arnold Bennett (1867-1931), Ida y vuelta (Outward Bound) (1924), de Sutton Vane (1888-i...?), Oriente y Occidente (East of Suez) (1922) de W. Somerset Maugham (1874-1965), Nunca puede decirse... I Nunca se sabe (You Never Can Tell) (1898), de George Bernard Shaw (1856-1950), El vórtice (The Vortex) (1924), de Noël Coward (1899-1973), más tres europeas, La carroza del Santísimo (Le carrosse du Saint Sacrement) (1829), de Prosper Mérimée (1803-1870), Hedda Gabler (1890), de Henrik Ibsen (1828-1906), y La flor en los ojos (Il fiore sotto gli occhi) (1921), de Fausto Mario Martini (1886-1931). Entre las obras extranjeras, varias de las traducciones eran del mismo Baeza: sabemos con seguridad su autoría de las versiones de Oriente y Occidente y Hedda Gabler, es probable que fuera el traductor de Amor sagrado y profano, y posible que lo fuera de Ida y vuelta y El vórtice ${ }^{45}$.

tral. Los planes de RB e ILH», El Sol, 8-XII-1927, p. 5, o ANÓNIMO, «El teatro. Notas informativas. Poliorama», El Día Gráfico (Barcelona), 5-IV-1928, p. 8. Hay que recordar que López Heredia hizo muchas temporadas con Ernesto Vilches en Hispanoaméri$\mathrm{ca}$, y el libro de Dougherty y Vilches se refiere exclusivamente a Madrid, abarcando el período 1918-1926, así que hay muchas otras posibilidades para montajes previos de estas obras.

43 No hemos podido averiguar si López Heredia ya había actuado en los montajes de Amores y amoríos y Mimí Valdés; en el primer caso parece muy probable que sí, dada la fecha y la popularidad de la obra; Mimí Valdés fue estrenado por Josefina Díaz de Artigas en junio 1926, así que en este caso cabe más duda.

44 Las principales fuentes son: ANÓNIMO, «Información teatral. Los planes de RB e ILH», El Sol, 8-XII-1927, p. 5, y ANÓNIMO, «El teatro. Notas informativas. Poliorama», El Día Gráfico (Barcelona), 5-IV-1928, p. 8.

45 En el curso de 1925-26, Baeza ya había propuesto a la compañía Vilches-López Heredia, Un héroe contemporáneo de Claudio de la Torre y sus versiones de Un marido ideal (Wilde), El camino de Francia (Milne), y Al este de Suez (= Oriente y Occi- 
Caben unos comentarios sobre este análisis de la oferta de la compañía. La táctica de dar primero comedias agradables efectivamente se puso en práctica. Si nos fijamos, por ejemplo, en las primeras actuaciones en Zaragoza y en Vitoria, vemos que el repertorio consistía en nueve obras «convencionales» (Amores y amoríos, El corazón manda, Lo cursi, Lady Frederick, La mala ley, María Victoria, Un marido ideal, Rosas de otoño y Tambor y cascabel) y sólo dos - la «farsa grotesca» La máscara y el rostro y El camino de Francia- que realmente podrían considerarse modernas o atrevidas. Si calculamos el número de representaciones en las mismas ciudades, las nueve obras «convencionales», combinadas, se dieron 42 veces, mientras que La máscara... se dio dos veces y El camino... una sola vez. Esta tendencia viene perfectamente confirmada en el segundo cuadro sinóptico (número de representaciones), donde vemos que entre los estrenos y/o las obras de orientación más experimental, puede decirse que únicamente El caballero Varoná se diera con cierta frecuencia ${ }^{46}$.

Pero esta distribución de obras y representaciones correspondía, desafortunadamente, no sólo a una estrategia de cambio gradual, sino también a consideraciones económicas más inmediatas. Irene López Heredia se encontraba en una posición difícil pero bastante típica: si por un lado quería sinceramente mejorar la oferta y hacer algo para paliar el decaimiento de la escena contemporánea, por otro tenía que recuperar su inversión en decorados y muebles, arrendar a los empresarios los teatros donde actuaba, pagar los sueldos de actores y técnicos, y un largo etcétera ${ }^{47}$. Su con-

dente) (Maugham). Uno de los atractivos de hacerse director artístico a finales de 1927 debe de haber sido la posibilidad - en teoría - de ejercer mayor control sobre el montaje de sus propias traducciones.

46 Véanse las reseñas positivas de esta obra: ANónIMO, «Alta comedia en el Tamberlick. La compañía de ILH. El caballero Varona», Faro de Vigo (Vigo), 19-II1928, p. 6; Juan A. CABEZAS, «El estreno de anoche. El caballero Varona», El Carbayón (Oviedo), 11-III-1928, p. 8; G. SANTELICES, «Los teatros. Lope de Vega. El caballero Varona, tres actos de Jacinto Grau», El Norte de Castilla (Valladolid), 25-III-1928, p. 4; E.G.C., «Por esos teatros. Poliorama. El caballero Varona, de Jacinto Grau», El Diluvio (Barcelona), 12-IV-1928, p. 35; M. RODRíGUEZ CODOLÁ, «Música y teatros. En el Poliorama. El caballero Varona. Obra, en tres actos, original de don Jacinto Grau Delgado», La Vanguardia (Barcelona), 13-IV-1928, p. 7.

47 En su carta sin fecha con membrete de un hotel de Santiago de Compostela, escrita un día después de representar El caballero Varona y dirigida a Baeza, López Heredia habla de los muchos gastos y de la necesidad de reducirlos. Un informe en la «Sección de rumores» del Heraldo de Madrid, 12-III-28, p. 5, se hace eco de estas preocupaciones: «Se dice: [...] Que la compañía de Irene López Heredia, con los aditamentos y mejoras que acaba de sufrir, lleva la nómina más alta de todas las compañías que hoy circulan por España. I-Que, en efecto, se permite lujos que parecen incompatibles con las actuales condiciones del negocio teatral en España [...] en su propósito de tener una compañía nunca igualada en España [...]. I -Que, efectivamente, estos actores de la compañía López Heredia cobran sueldos hasta ahora desconocidos en nuestra escena [...]. I-Que si se une a ello el sueldo que sin duda debe llevar el señor Baeza, como 
ciencia de la poca flexibilidad del público $-\mathrm{y}$ de los efectos crematísticos consiguientes - se refleja tanto en la lenta «preparación del terreno» como en los rápidos cambios de cartelera.

De esta manera, cuando La máscara y el rostro se montó en Zaragoza el 23 (noche) y 24 (tarde) de diciembre de 1927, Ricardo Baeza publicó un largo artículo explicatorio y apologético sobre la obra en el periódico principal ${ }^{48}$, y la siguiente vez que la compañía la repuso, en Vigo el 29 de enero de 1928 (tarde y noche), esa mañana en un periódico vigués apareció el mismo ensayo de Baeza ${ }^{49}$. A pesar de estas «medidas preventivas», la obra recibió en Zaragoza una acogida tibia, con una mezcla de elogios y censuras ${ }^{50}$, y llama la atención el que en las dos ocasiones siguientes cuando fue programada, en ambos casos (Vigo, 29 de enero; Oviedo, 15 de marzo) se representara el último día de la temporada, posiblemente para que hiciera menos daño a la taquilla.

Esa atribución de motivos puede parecer arriesgada, sin embargo se observa exactamente el mismo tipo de consideración y procedimiento aplicados en las sustituciones repentinas: cuando en Zaragoza el 9 de enero (¡otro día fin de temporada!) el estreno de El camino de Francia gustó muy poco en la sesión de la tarde, fue reemplazado inmediatamente en la sesión de la noche por una obra «probada», Tambor y cascabel $^{51}$. Además, encontramos un caso paralelo durante la actuación barcelonesa: Entre gente bien se estrenó el 25 de abril (sesión de noche), tuvo dos representaciones más el día 26, pero la representación programada para la sesión de noche del 27 fue cancelada, siendo reemplazada por otra obra «segura», Un marido ideal. Este hecho no es difícil de explicar, ya que la obra de Maugham recibió una reseña hostil el 26 y dos más el 27, además de ser, al decir de los críticos, rechazada por los espectadores ${ }^{52}$.

corresponde a su jerarquía, y lo que deben costar los decorados de Bartolozzi y Fontanals, no es de extrañar que la nómina de la señora López Heredia ascienda a una cifra realmente espantable».

48 Ricardo BAEZA, «El teatro. La máscara y el rostro», Heraldo de Aragón (Zaragoza), 23-XII-1927, p. 5.

49 Ricardo BAEZA, «El teatro italiano moderno. La máscara y el rostro», Faro de Vigo (Vigo), 29-I-1928, p. 7.

50 M. Álvarez, «En los teatros. Principal. La máscara y el rostro», Heraldo de Aragón (Zaragoza), 24-XII-1927, p. 2; A.M., «Teatros. Principal. La máscara y el rostro», El Noticiero (Zaragoza), 24-XII-1927, p. 5; J.S.R., «Los teatros. Principal. Estreno de La máscara y el rostro», La Voz de Aragón (Zaragoza), 24 diciembre 1927, p. 10.

51 M. Álvarez, «En los teatros. Principal. Beneficio de ILH y despedida de la compañía», Heraldo de Aragón (Zaragoza), 10-I-1928, p. 5; BILLY, «Teatros. Principal. El camino de Francia», El Noticiero (Zaragoza), 10-I-1928, p. 7; J.S.R., «Los teatros. Principal. El estreno de El camino de Francia y beneficio de ILH», La Voz de Aragón (Zaragoza), 10-I-1928, p. 10.

${ }_{52}$ M.S.C., «Por esos teatros. Poliorama. Estreno de la comedia de costumbres hispano-americanas en tres actos Entre gente bien, adaptada de una obra de J.W. Somerset 
Estas experiencias confirmaron las opiniones que Salvador Bartolozzi había expresado en una carta dirigida a Baeza fechada el 3 de enero de 1928: tras ponderar las dificultades de ofrecer buen teatro y las aun mayores de introducir «audacias» en la cartelera, concluyó, como para distanciarse de toda responsabilidad, que «de todos modos, yo advertí a Irene, antes de empezar, a lo que se exponía» ${ }^{53}$.

De hecho, al leer las muchas reseñas aparecidas en la prensa de la docena de ciudades que visitaron, uno tiene la impresión de un horizonte de expectativas bastante rígido y esencialmente fijado de antemano. Todas las calidades de López Heredia como actriz son elogiadas repetidamente, en una serie de giros retóricos consabidos, mientras que a Baeza se le describe como «ilustre escritor», «el ilustre crítico y adaptador de obras teatrales», «el acreditado crítico, autoridad en el estudio del teatro de vanguardia», «una de las supremas autoridades españolas en materia teatral, $\mathrm{y}$, además distinguido articúlista y ensayista» o, más escuetamente, «un paladín del teatro». También es llamativo el que se refieran a la agrupación, no siempre como la compañía o compañía dramática de López Heredia, sino a veces como la Compañía de Alta Comedia, como si se diferenciara en esto de una compañía de ópera o de zarzuela. Y como hemos visto, la «alta comedia» era precisamente su especialidad, una especialidad difícil de cambiar, variar o ensanchar, aunque existiera el deseo de hacerlo, por la oposición de una férrea ley de oferta y demanda.

Estas trabas de un convencionalismo arraigado tanto, quizás, en los instintos de la primera actriz como en los gustos y las preferencias de un público provinciano, llegaron incluso a afectar al más «libre-pensador» entre ellos, Ricardo Baeza ${ }^{54}$. Después de examinar el repertorio inusitado de la otra compañía dramática que había capitaneado, la «Atenea» de $1919,{ }^{55}$ y después de leer algunos de sus numerosos artículos, frecuentemente mordaces, publicados en El Sol y la Revista de Occidente durante los años 20,

[sic] por Ricardo Baeza», El Diluvio (Barcelona), 26-IV-1928, p. 29; Diego MONTANER, «El teatro. Poliorama. Entre gente bien (Our betters) original de W.S. Maugham.-Adaptación de Ricardo Baeza», El Día Gráfico (Barcelona), 27-IV-1928, p. 8; ANóNIMO, «Música y teatros. Barcelona. Entre gente bien. Comedia de costumbres hispanoamericanas, en tres actos, adaptada de una obra de J.W. Somerset [sic], por don Ricardo Baeza», La Vanguardia (Barcelona), 27-IV-1928, p. 26.

53 Archivo Baeza.

54 Comentó un periodista al anunciarse la empresa: «No hay que decir que interviniendo Baeza en el negocio, la orientación de la compañía será modernísima»: ANóNIMO, «Crónicas y noticias teatrales de "Informaciones". Las brujas informadoras. Aquelarre teatral», Informaciones, 5-XII-1927, p. 9.

55 Véase Andrew A. ANDERSON, «Una iniciativa teatral: Ricardo Baeza y su Compañía Dramática “Atenea" (1919)», en De lo particular a lo universal. El teatro espanol del siglo XX y su contexto, ed. John P. Gabriele, Frankfurt am Main, Vervuert Verlag, 1994, pp. 29-40. 
cuesta trabajo pensar que realmente hubiera querido participar activamente en una iniciativa que se apoyaba en dramaturgos como los hermanos Álvarez Quintero, Linares Rivas y Benavente. Pero tal era efectivamente el caso, llegando al extremo de ufanarse de que «[Eduardo] Marquina nos ha prometido una obra para la primavera» ${ }^{56}$ y de expresar la esperanza de recibir obras especialmente escritas para López Heredia por Benavente, los Álvarez Quintero y Linares Rivas ${ }^{57}$. Pero todo es relativo, como prueba el que escribiera un crítico de Pontevedra que «Benavente, porque no llegó todavía a escribir para todos, no se amolda a los gustos del público» ${ }^{58}$. Baeza quizás había comprendido que para combatir las vulgaridades ramplonas, la comicidad soez y la intrascendencia empecinada del astracán, de la «baja comedia» por decirlo así, no hacía falta un Strindberg, ni un Cocteau ni un Pirandello, platos demasiado fuertes para la mayoría de los públicos ${ }^{59}$; más bien, empezando con algunas de las obras de mayor calidad de Benavente o los Álvarez Quinteró, se podría tratar de intercalar, de vez en cuando, una obra algo más «artística», de más médula y visión ${ }^{60}$.

Por lo menos, ese era el plan. Pero la duración de la colaboración, unos escasos cinco meses, demuestra que hubo más problemas, como ya se ha insinuado. López Heredia mantenía una mentalidad abierta - como prueba el que estuviera dispuesta a estrenar a Grau, conocido en círculos teatrales como gafe, y como probaría de nuevo su estreno de dos obras de ValleInclán en 1931-, pero abierta sólo hasta cierto punto. Baeza, por su parte, debió ser bastante más idealista, y a pesar de sus experiencias como

56 ANÓNIMO, «Información teatral. Los planes de RB e ILH», El Sol, 8-XII-1927, p. 5.

57 Emilio CERRILLO, «Entrevistas. Hablando con RB. El valor más importante del teatro español es Jacinto Grau», El Norte de Castilla (Valladolid), 25-III-1928, p. 3. En el archivo Baeza se conservan cartas de los hermanos Álvarez Quintero (2-XII-1927) donde dicen que no pueden prometer una obra nueva, y de Linares Rivas (2-I-1928) donde dice que espera escribir una obra nueva para Irene.

58 ANÓNIMO, "Al borde de las tablas. Rosas de otoño», El Diario de Pontevedra (Pontevedra), 29-II-1928, p. 2.

59 Afirman Dru DoUgherTy y María Francisca VILCHES DE FruTos que «El gusto mayoritario se decantó durante estos años por un género de obras cómicas, generalmente en un acto, que tenían en común lo disparatado de sus situaciones, a menudo rayando lo procaz, un ingenioso juego lingüístico, plagado de diálogos picantes, un gran despliegue de medios escenográficos, música y bailes, que hacían las delicias del público»: La escena madrileña entre 1918 y 1926. Análisis y documentación, Madrid, Fundamentos, 1990, pp. 87-88. Su extensa introducción ofrece un excelente marco para nuestros comentarios, y es de notar que un alto porcentaje de los autores exitosos está formado por nombres completamente desconocidos para nosotros hoy en día. Estas observaciones se aplican también al análisis detenido que ofrece el segundo tomo: María Francisca VILCHES DE FRUTOS y Dru DOUGHTERTY, La escena madrileña entre 1926 y 1931. Un lustro de transición, Madrid, Fundamentos, 1997.

60 Para una visión de conjunto sobre el teatro español y lo que faltaba en la escena, véase GAZIEL, «Pláticas literarias. Teatro y democracia», El Sol, 19-I-1928, p. 1. 
director artístico en 1919 y como traductor con Mimí Aguglia en $1926^{61}$, vivía el teatro esencialmente desde el auditorio, el podio y el gabinete, como crítico, ensayista, conferenciante, traductor y lector. No es muy difícil imaginar su creciente frustración, dado el número reducido de estrenos interesantes y la poca frecuencia con que volvían a las tablas. Aunque es imposible trazar sus movimientos con toda exactitud, parece que a medida que pasaba el tiempo, Baeza abandonaba la compañía cada vez más para volver a Madrid.

En el lento deterioro de las relaciones - reflejado en el aumento de las transigencias artísticas-, la temporada de Pascua de Barcelona, evidentemente, representa un momento decisivo, aunque el principio de los problemas puede fecharse bastante antes. Disponemos de una visión interna, aunque sólo parcial, del pensamiento de Baeza durante la primavera de 1928 gracias a una serie de cartas de Claudio de la Torre dirigidas a Baeza ${ }^{62}$ : la otra parte de la correspondencia está perdida, pero a menudo es fácil inferir los comentarios de Baeza a base de las respuestas de De la Torre. La primera señal de desacuerdo y de desánimo aflora en una carta de éste del 29 de marzo, que contesta una de Baeza del día 26, escrita cuando él y la compañía se encontraban en Valladolid, terminando ya su breve temporada allí ${ }^{63}$. Por su pertinencia e interés, creemos que esta carta merece citarse in extenso:

Y que este [éxito] y otros le animen a usted a seguir. No estoy conforme con sus vacilaciones. Hay que vivir en la única realidad que tenemos. Bastante hará usted, para el aprecio de las gentes, si al final de la temporada ha dado a conocer al público una o dos obras, nada más. Ni esto dan las otras compañías. Esas obras, sin usted, hubieran permanecido inéditas mucho tiempo. Ya es bastante adelantarles su vida en unos cuantos años. Otra cosa es halagarse con sueños inútiles, cómodamente, sin acción, proyectar y proyectar toda la vida. O desconocer, totalmente, la reforma profunda que necesitan nuestros públicos y nuestros empresarios, más éstos que aquéllos a mi juicio. Pero las guerras se hacen en los campos de batalla, o no se va a la guerra. $Y$ usted ya nos demuestra que es un buen general. Cada obra fuera del repertorio general es una conquista para todos. Insensiblemente, poco a poco, se encontrará us-

61 Andrew A. ANDERSON, «Ricardo Baeza y el teatro», Anales de la Literatura Española Contemporánea, XIX, núm. 3 (1994), 229-240 (pp. 231-233).

${ }_{62}$ Archivo Baeza. Claudio de la Torre se encontraba en París, donde colaboraba en las preparaciones para el montaje de Tic-Tac por Aurélien-Marie Lugné-Poë en el Théâtre de l'Oeuvre, repetidamente postergado por el centenario de Ibsen que se celebraba en aquel entonces. Baeza, por su parte, consideraba la posibilidad de estrenar Tic-Tac -o de reponer Un héroe contemporáneo- en Barcelona.

63 El 27 de marzo Baeza repitió en Valladolid su conferencia sobre «El carro de Tespis». Allí debe de haber pasado toda la semana de la temporada: ANóNIMO, «RB.

1. Su estancia en Valladolid», El Norte de Castilla (Valladolid), 23-III-1928, p. 6; Emilio CERRILLO, «Entrevistas. Hablando con RB. El valor más importante del teatro español es Jacinto Grau», El Norte de Castilla (Valladolid), 25-III-1928, p. 3. 
ted dueño del campo, más cerca de la última conquista, por lo menos: la de las empresas. Pero sin impaciencias, con tacto, y procurando no equivocarse. Cada éxito de una obra «suya» adelanta en cinco años la reforma teatral. $\mathrm{Si}$ usted no lo supiera le seguiría argumentando. Pero basta de sermón.

No obstante la elocuencia de su argumentación, las «vacilaciones» de Baeza se mantuvieron en pie y crecieron, como demuestra el siguiente intercambio de cartas. Claudio de la Torre le escribió el 12 de abril, contestando una misiva del día 8 , redactada (casi seguramente desde Madrid) un día después de la inauguración de la temporada barcelonesa:

En cuanto a su dimisión, supongo lo que no me dice. Pero lo siento. Menos mal si puede ahora trabajar en lo suyo y dirigir, de lejos, la actividad de la compañía. Dos cosas ganaremos en lugar de una.

Como se desprende de la cita, la «dimisión» de Baeza no era absoluta, sino que le permitía volver a «lo suyo» (traducciones, publicaciones, periodismo, etc.) mientras guiaba «a distancia» la orientación artística de la compañía. Siguen dos cartas, ambas sin fecha, de López Heredia (en Barcelona) a Baeza (en Madrid). En una le recrimina:

No me puedo creer que no sea Ud. capaz de ponerme una sola letra con los días que hace que se fue de mi lado. [...] Haga el favor, querido, de quererme un poco mejor, por lo menos como yo le quiero a Ud...

aunque a la vez queda claro que Baeza seguía sirviendo como consejero y agente suyo:

No tenemos nada para ensayar. ¿Qué hacemos? ¿Pongo en ensayo Cándida y ya se reformará en algo cuando Ud. venga?

Y hágame caritas y saque obras buenas aunque sea del fondo de la tierra que me da mucho pánico la temporada de Barcelona ${ }^{64}$.

En la otra, que podría ser posterior, ella se discupla por no haber escrito antes, le asegura que continúa siendo su buena amiga y que le considera un hombre de talento, y le da muchas gracias por sus buenos consejos, los cuales intentará seguir si le es posible.

Pero esta tregua provisional no iba a durar mucho tiempo. El 23 de abril Baeza se encontraba en Barcelona, como atestigua la dedicatoria de un libro firmada en tal fecha ${ }^{65}$. Dos días después se celebró el estreno de

64 A continuación preguntaba si Baeza había ido a ver a Benavente, los Quintero, Honorio Maura y Linares Rivas. Hay que comparar el tono de esta misiva al de una carta previa, del 26-27 febrero, enviada desde Santiago de Compostela, donde López Heredia acusa recibo de «su gratísima, larguísima y simpatiquísima carta».

65 Archivo/biblioteca Baeza. El libro es de Alicio Garcitoral, Notas sobre Portugal, dedicado a Baeza y anotado «B / 23 / 4/ 928». Con referencia a Entre gente bien, ya se había anunciado que «Ricardo Baeza vendrá a los ensayos generales y al estreno»: ANÓNIMO, «Música y teatros...», La Vanguardia (Barcelona), 15-IV-1928, p. 27. 
Entre gente bien, dirigido por él y en adaptación suya, estreno que, como hemos apuntado, recibió la acogida más negativa de las 19 obras montadas. La pieza de Maugham tuvo tres representaciones antes de ser sustituida, y sospechamos que a raíz de este fracaso, y quizás de desacuerdos que surgieran como consecuencia, sobre esta decisión y sobre el futuro repertorio de la compañía, sobreviniera la ruptura definitiva. De «vacilaciones» a «dimisión» ahora pasamos a la renuncia total, como se registra en otra carta de De la Torre fechada el 14 de mayo:

Sus noticias, aun al traer la de la renuncia sospechada, me causan la impresión de su contento al reanudar su vida, frente a frente, de nuevo, a sus cuartillas, sus sueños y proyectos.

Añade que su breve experiencia en el teatro también ha sido amarga (alude a los constantes retrasos del montaje parisiense) y le anima refiriéndose a «sus planes editoriales reanudados» $\mathrm{y}$ «la proximidad probable de sus libros».

El fin de la colaboración, que precedió por poco al fin de la actuación en Barcelona, tuvo unas repercusiones rencorosas. Para los últimos tres días de la temporada - 19, 20 y 21 de mayo- estaban programadas, según la costumbre de López Heredia, las seis primeras representaciones de Cándi$d a$, de Bernard Shaw. Pero varios telefonemas del 17 y 18 de mayo muestran que Baeza procuró impedir tal estreno, no sabemos por qué motivos exactamente, pero seguramente relacionados con la ruptura ${ }^{66}$. En el primero, del día 17, López Heredia acudió al traductor de la obra, Julio Broutá, en la Sociedad de Autores de Madrid:

Después grandes gastos para montar Cándida Beneficio Baeza por asuntos particulares no sé con qué derecho me la suspende le suplico me autorice Vd. pues estoy desesperada último momento cuente con eterno agradecimiento L.H.

El segundo, enviado el 18 de mayo por un tal Pedro Masaveu desde Oviedo a Baeza en Madrid, demuestra que López Heredia también se dirigió a amigos de éste para que intervinieran por ella ante él. Finalmente, uno dirigido directamente por Heredia a Baeza, también del 18, reza así:

Norro dará una convenida esperando de su bondad probada acceda este nuevo favor autorizando Cándida confiada en condescendencia cordialmente le saluda esperando ansiosa su respuesta.

No se sabe qué pasó luego — si Baeza accedió o si Heredia encontró una manera de pasar por encima de él-, pero de todas maneras las seis representaciones sí tuvieron lugar a partir del 19 de ese mes.

66 Todos los telefonemas están en el archivo Baeza. 
Al año siguiente, López Heredia, con un primer actor nuevo, Mariano Asquerino, contrataría a Cipriano Rivas Cherif como director artístico para acompañarles en una gira por Argentina y Uruguay ${ }^{67}$. Desgraciadamente, después de varios éxitos, esa iniciativa terminó de manera casi idéntica, por desacuerdos entre ellos esta vez sobre la programación de El alfiler, de Pedro Muñoz Seca ${ }^{68}$. Los problemas encontrados por Baeza y por Rivas Cherif nos hablan elocuentemente del estado de la escena española de la época, y nos demuestran cuán difícil resultaba combinar un proyecto comercial económicamente viable con unos criterios artísticos medianamente exigentes. Ese «tercer camino» que mencionamos al principio, no era fácil de localizar, y una vez encontrado se notaba que estaba lleno de obstáculos y baches. Desde el punto de vista estratégico, creemos que Baeza acertó al optar por la «infiltración» en lugar de la confrontación, pero queda claro que el tiempo necesario para ver aun los primeros resultados de sus intentos de reforma era bastante más largo que unos escasos cinco meses, mientras bajo otra óptica hay que reconocer que los esfuerzos de una sola compañía nunca iban a transformar radicalmente el sistema teatral. Aunque muchas de las metas de la campaña inevitablemente se frustraron, por las razones aquí analizadas, los propósitos y las experiencias de Baeza y López Heredia forman un episodio importante y revelador en la accidentada historia del teatro español de entreguerras, episodio que merece incluirse al lado de otras iniciativas coetáneas mejor documentadas.

\footnotetext{
67 En la primavera de 1928 López Heredia ya tenía este plan: «—En el año 1929 es posible, aunque todavía no se puede afirmar, que hagamos una excursión a América, deteniéndonos durante largo tiempo en Buenos Aires», en Emilio CERRILlo, «Entrevistas. ILH, la bellísima actriz, nos dice...», El Norte de Castilla (Valladolid), 27-III-1928, p. 1.

68 Cipriano DE RIVAS CHERIF, Cómo hacer teatro..., pp. 41-42 (y nota 9), p. 186. Véase Andrew A. Anderson, "Coincidencias y paralelismos: las carreras teatrales de Ricardo Baeza y Cipriano Rivas Cherif», en Actas del XII Congreso Internacional de Hispanistas. Birmingham 1995, vol. IV: Del Romanticismo a la Guerra Civil, edición de Derek W. Flitter, Birmingham, Department of Hispanic Studies-The University of Birmingham, 1998, pp. 41-49.
} 